\title{
OBITUARY
}

\section{O.R. Frisch, 1904-1979}

ON 22 September 1979 Professor Otto Robert Frisch, OBE, FRS, Emeritus Jacksonian Professor in the University of Cambridge, died following an accident. $\mathrm{He}$ was a distinguished and original nuclear physicist. His contributions to physics will be, and the example he set in his approach to the subject should be, remembered by future physicists.

Both in physics and in music, which was next to physics his strongest interest, his main driving force was enjoyment of what he was doing. In physics this meant using simple apparatus, preferably designed and made by himself, and looking for important problems with transparent answers. Some of the instruments he made might be called gadgets, but surprisingly often these gadgets were able to provide answers to topical problems. Naturally "big physics"' was not his line, and he never became involved with projects needing large machines and large teams of collaborators.

His piano playing was of nearprofessional standard, but he was not a perfectionist, and was not above listening to, or playing with, musicians of a much lower calibre, provided they shared his enjoyment of the result.

He was born on 1 October 1904 in Vienna. His father, Justinian Frisch, was a printer, his mother a very gifted musician. I do not know whether his father's profession influenced his interest in writing and his flair for the written word, but no doubt his mother encouraged his music. The members of the family were very close, and all his life he remained in touch with his relatives. Above all he was very close to his aunt, Lise Meitner, the famous nuclear physicist.

At school Otto Robert (as he was known to the family; later he was just Robert to his friends, except for the Los Alamos period, when there were too many Roberts around, and he became Otto) showed marked ability in mathematics, and almost chose it as a career, but in the end decided that this would be too abstract for his taste, and he settled for physics.

His studies in the University of Vienna under Professor Karl Przibram appear to have been uneventful, and he obtained his D Phil in 1926, after four years in the university. This was rapid progress, but at the time not unusual. After a year in a small firm run by an inventor, where he presumably could indulge in his love for gadgets, he accepted a post in the Physikalisch-Technische Reichsanstalt in Berlin. His work there was in the optics division, with the assignment to work on a proposed new light standard, but he says "I stayed long hours trying out half-baked

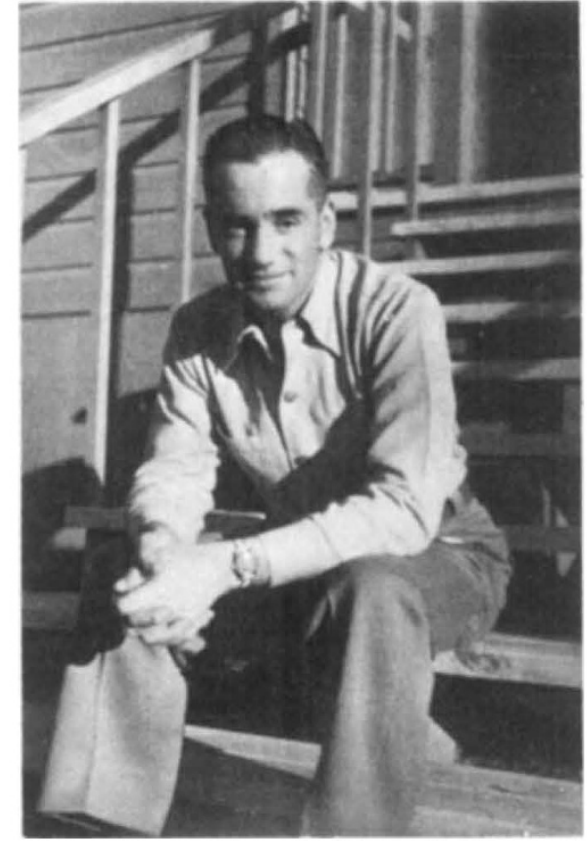

ideas of my own". His assignment was hardly exciting, but he was able to attend seminar meetings at the university, and listen to remarks by Einstein, Planck, Nernst and others. Lise Meitner was there, too. She worked, and lived, in the suburb of Dahlem, but Frisch saw her frequently, to the profit of his physics and his music.

In 1930 he became an assistant to Otto Stern in Hamburg, famous for the SternGerlach experiment. Stern was an outstanding experimenter, not in manual skill, but in his command of the relevant principles and in the design of experiments, and his laboratory was the leading one in the world for atomic-beam research. Frisch worked closely with him and took part in important experiments, including the first observation of the diffraction of atomic beams by crystal surfaces. At the end of his Hamburg period he did his first important experiment on his own, observing the recoil of atoms on photon emission.

But by this time the Nazi government was in power, and both Stern and Frisch, who were of Jewish descent, had to leave. Frisch went to Birkbeck College to work under Blackett with a grant from the Academic Assistance Council. Here he became interested in nuclear physics, which in 1933 was full of excitement. He invented a method of measuring very short-lived activities, and this led to the discovery of some new radioactive isotopes.

A year later, Niels Bohr, who must have heard of his ingenuity in devising and carrying out experiments, invited him to Copenhagen. The next five years in the informal and stimulating atmosphere of
Bohr's Institute were very fruitful. It was the time when neutron physics had been initiated by Fermi's work, and Frisch, too, started on neutron work. Probably he was drawn in initially because he happened to have the most appropriate counter with which to test for neutron-induced activity. He made many important contributions to that subject.

It was in neutron physics that he did his most famous piece of work. He was spending Christmas 1938 with Lise Meitner, who was now in Sweden. She received a letter from Otto Hahn, with whom she had collaborated closely until she had to leave Germany, telling her of his discovery that barium was among the products emitted when uranium was bombarded with neutrons. Hahn realised this meant that the uranium nucleus must have split into two large pieces. Frisch and Lise Meitner were as dumbfounded by this news as all other physicists when they heard of it. But after thinking about the discovery for a while, they understood how the strong electric charge could help to overcome the suface tension and lead to an unstable configuration once the nucleus was set vibrating by a collision. If the nucleus had taken a sufficiently elongated form the mutual repulsion of the positive charges would drive it apart, and this would release an energy of about $200 \mathrm{MeV}$. Frisch coined the word "fission" for this process. After returning to Copenhagen and composing a letter to Nature jointly with Lise Meitner over the telephone to Stockholm, he carried out an impressively simple experiment proving the emission of energetic and heavily ionizing particles from the bombarded uranium, and thus confirmed the interpretation.

Fission was now the exciting part of nuclear physics, and most nuclear physics laboratories started to work on this. Frisch continued in this field, too, and did several more important experiments.

But this was 1939. War was imminent, and Denmark not too healthy a place for a German refugee. (The Anschluss had made him a German subject). Besides, the Danish police were making difficulties about extending his permit. So he tried to find a place in England, and, when Oliphant heard of his problem, he arranged an appointment for him in the University of Birmingham. Here Oliphant was trying to build up facilities for nuclear physics work, but there was not much equipment as yet, and Frisch could not continue his experimental work immediately. But he continued speculating about fission.

The possibility of the release of nuclear energy was then in many people's minds, 
once it had been shown that neutrons were emitted after the fission. One was awed by the thought of a new weapon of terrifying power, but Frisch, like others who had understood the paper by Bohr and Wheeler on the mechanism of fission, and Bohr's argument that the fission caused by slow neutrons was due to the rare isotope ${ }^{235} \mathrm{U}$, were reassured that no violent explosion could happen in ordinary uranium. The thought of separating uranium isotopes in large quantities seemed to belong to science fiction. Then one day Frisch came to me and said "Suppose one had a large amount of separated ${ }^{235} \mathrm{U}$, what would happen?" One could make a guess at the fission cross section from the ideas of Bohr, and I knew how to estimate the critical size, given the cross section. The answer staggered us by being smaller than we would have guessed. Next we had to estimate how far the chain reaction would proceed before the energy it released would drive the uranium apart. The answer again staggered us by being a reasonable fraction of the total energy available. If that was so, we said, it would be, as a weapon, worth its price, even if the isotope separation plant cost as much as a battleship (this turned out to be an underestimate). What if the Germans got there first and a nuclear bomb was in the hands of Hitler's Germany?

We wrote down our arguments, and that was the start of serious interest in atomic energy work in England. Frisch first tried to explore the possibility of isotope separation by thermal diffusion, but did not get far, and we now know that the thermal diffusion coefficient in the only gaseous uranium compound happens to be practically zero. Instead Frisch moved to Liverpool, where in Chadwick's laboratory there was a cyclotron and other facilities for nuclear physics, and worked on the nuclear physics aspects of atomic energy until the end of 1943, when it was decided to discontinue work in England and move to America those who could be useful to the American work.

So Frisch went to Los Alamos, the strange atom-bomb city in the middle of New Mexico. He was not attached to any specialist team but had a roving assignment and in that way was able to give essential help to many different groups. One of the experiments he set up himself was a typically original scheme known as the dragon. Two pieces of fissile material which together would make a critical mass and so cause a violent chain reaction, were allowed near each other for only a short moment, by dropping one piece past the other. The speed was so arranged that the chain reaction did not develop to any dangerous degree. The name indicated that one was tickling the tail of a dragon. The experiment made it possible to observe details of a near-critical situation which were otherwise hard to get at.

After the war, Frisch returned to England and became head of the Nuclear Physics Division at Harwell. Adminis- tration was not his favourite pastime, but he found that his deputy Dr (later Sir) Robert Cockburn delighted in running things and did it well. Frisch left Harwell in 1947 to become the Jacksonian Professor of Physics in Cambridge and a Fellow of Trinity. At that time nuclear physics in Cambridge was overshadowed by cystallography and other lines. It was not in Frisch's character to fight for more support. Besides, nuclear physics had now become big physics and less to his taste. While he kept a lively interest in nuclear physics and in the newly developing particle physics, he spent more of his time teaching and writing. Many students profited from contact with his way of doing and looking at things. He still liked gadgets, and made many ingenious instruments. His writing included Meet the Atoms, a very readable popular introduction to modern physics. Only a few months ago he published his recollections under the appealing title What little I remember, ${ }^{1}$ and it is pleasing that he was able to leave this lively record of his personality.

Shortly after moving to Cambridge he married, and there were two children. His wife shared not only his Austrian origin, but very many of his attitudes and his love for music.

Shortly before retiring in 1972 he invented an apparatus for measuring and evaluating bubble-chamber tracks, and he later became a partner in a firm set up to manufacture this. I do not know whether this commercial activity made him a wealthy man, but he clearly enjoyed this novel position and seeing his gadget being produced.

His was a full life, but he just failed to reach his seventy-fifth birthday with its warm messages from his many friends.

Rudolf Peierls

1. Frisch, O.R. What Little I Remember. (Cambridge University Press, 1979) See review by Rudolf Peierls in Nature 280, 257-259 (19 July 1979).

\section{Martin Lüscher}

IN THE midst of his fruitful work, Martin Lüscher's life was taken on 9 August 1979 by a tragic accident, at the age of 63 . He was Professor of Zoology at the University of Berne, and directed its Department of Zoophysiology with scientific foresight and a fatherly concern for his colleagues and students. His name will be remembered by zoologists throughout the world.

Martin Lüscher, son of the Basle artist Jean-Jacques Lüscher, spent a quiet youth in his family home, with extended visits to Provence. There, the harmony and beauty of the landscape created a lasting impression on him; in the balmy
Mediterranean atmosphere with the colour play and diverse insect cacophony in the flower fields he developed a love and interest of plants and animals. In Basel in 1944 he was awarded a PhD in zoology. After his marriage to Noemi Stoecklin, daughter of the Basle artist Niklaus Stoecklin, which proved to be a true life partnership, he began, with her, his lifelong progress as a zoologist. They shared a life of work, pleasures and trials. A great deal of his professional success was due to his close accord with his wife, with guests always welcome at their home.

As a young zoologist, Lüscher's first post was as a research assistant in Berne, where he worked under F.E. Lehmann on the physiology of development of amphibians. Soon afterwards he met his great teacher, the insect physiologist, $\mathrm{Sir}$ Vincent Wigglesworth of Cambridge, under whom he was able to work. Martin Lüscher saw Wigglesworth as the founder of a new branch of research: experimental insect physiology.

From England Lüscher moved to Paris, where he was introduced to the biology of termites by the renowned termite specialist T.P. Grasse and found the stimulus for what was to become his principal research - caste formation in termite colonies. He wished to study termites in the field as well as the laboratory, and he soon had the opportunity to take part in an expedition to observe at first hand the highly organised termite colonies of Africa. Lüscher was particularly fascinated by the highly elaborate nest structures built by the millions of termites within the colony. $\mathrm{He}$ was the first to understand their design as a well planned respiratory system with temperature and humidity regulation, and an air circulation system functioning through the warming of the air inside the nest. After imaginative and productive field work he spent a very important year of study in the United States on a grant from the Rockefeller Foundation. He was given the opportunity to stay for some time with A.E. Emerson, the expert on termite biology and taxonomy, and was then able to acquaint himself with modern methods of insect endocrinology in the leading laboratories at Berkeley, and at Harvard with C.M. Williams. Afterwards he worked at the Swiss Tropical Institute in Basel and in 1954 was appointed professor at the University of Berne. Under his direction the new Department of Zoophysiology was formed.

In 1965 he was appointed to the fouryear directorship of the Zoological Institute. During the academic year $1967 / 68$ he was Dean of the natural science faculty and from 1969 a member of the Swiss National Science Foundation. In his last important undertaking, in Nairobi as project leader at the newly founded International Centre of Insect Physiology and Ecology, he set up an enthusiastic research team.

Lüscher carried his title with quiet 